\title{
Representações cartográficas e suas implicações cognitivas
}

\author{
Isabel Jungk'
}

\begin{abstract}
Resumo: O artigo abre novas perspectivas sobre o potencial semiótico e os efeitos cognitivos dos mapas. Ele estuda as representações cartográficas a partir de uma perspectiva cartossemiótica. O seu foco está nos aspectos icônicos, especialmente diagramáticos, indexicais e simbólicos dos mapas. Seguindo a trajetória de suas principais formas de representação, das mais antigas até as mais recentes e inovadoras, o trabalho mostra a relevância da semiótica de Charles S. Peirce para o estudo dos mapas.
\end{abstract}

Palavras-chave: Cartossemiótica. Cognição cartográfica. Cartografia semiótica, C.S. Peirce.

\section{Cartographic representations and their cognitive implications}

Abstract: The paper opens new perspectives on the semiotic potential and cognitive effects of maps. It studies cartographic representation from the perspective of cartosemiotics. The focus is on the diagrammaticity and other iconic aspects of maps as well as on their indexical and symbolic signs. Following the trajectory of its main forms of representation, from the oldest to the most recent and innovative ones, the paper shows the relevance of C. S. Peirce's semiotics in the study of maps.

Keywords: Applied semiotics. Cartosemiotics. Map cognition. Semiotic cartography. C. S. Peirce.

I Isabel Jungk é Doutora em Tecnologias da Inteligência e Design Digital e Mestre em Comunicação e Semiótica pela PUC-SP. CV Lattes: lattes.cnpq.br/2830878145479718.

E-mail: isabeljungk@yahoo.com.br. 


\section{Os propósitos da cartossemiótica}

O propósito deste estudo ${ }^{2}$ é a análise semiótica das representações cartográficas. Somente a partir do século XX, os mapas passaram a ser objeto de considerações semióticas. Na segunda metade do século XX, surgiu a cartossemiótica como vertente semiótica da cartografia (cf. NöTH, I998). Um pioneiro da cartossemiótica foi o cartógrafo francês Jacques Bertin (I9I8-20I0), e o estudo semiótico dos mapas recebeu novos impulsos a partir de seu livro Sémiologie graphique (ig67). Sem se afiliar a qualquer escola específica de semiótica e sem adotar o linguocentrismo da semiótica francesa, Bertin desenvolveu um sistema de constituintes mínimos da representação cartográfica, tais como componentes invariantes elementares (ponto, linha, superfície e cor) e suas variáveis (tamanho, luminosidade e direção) (cf. NöTH, I998, p. I20-I2I). Ao estudar a cartografia como um sistema semiótico, Bertin procurou mostrar as diferenças específicas entre mapas e outros sistemas de representação, constatando que os mapas são sistemas "monossemióticos", compostos por signos elementares definidos como signos de significação inequívoca. Para Bertin, a características específicas dos signos cartográficos são os seus modos de representação gráfica e percepção visual. Segundo Krampen (I994, p. 98), a cartossemiótica do seu tempo considerou os mapas como uma forma de linguagem visual não verbal, tal como as notações musicais. No seu artigo sobre a relevância da semiótica para a cartografia, Krampen deu o seguinte resumo:

A cartografia é uma disciplina que pertence àquela parte da comunicação gráfica que se dirige ao canal visual e que concerne à transmissão de dados (científicos) ou outras informações em contraste com o uso artístico da comunicação gráfica, que transmite informação estética. Ela tira proveito do fato de que a percepção visual tridimensional vislumbra de uma só vez as inter-relações e a distribuição de muitos pontos qualitativamente diferentes sobre uma superfície, ao passo que a leitura e percepção aural estão limitadas ao processamento linear de uma porção de diferentes sons ou letras de cada vez. (KRAMPEN, I994, p. 98)

2 Agradeço a Daniel Melo Ribeiro, Guilherme Cestari e Winfried Nöth pelas sugestões e comentários que contribuíram para este artigo. Possíveis equívocos remanescentes são exclusivamente de minha responsabilidade. 
A informação dos mapas é captada de maneira diferente daquela típica da leitura linear demandada pela linguagem verbal, gerando efeitos cognitivos de natureza diversa. No estudo da eficácia visual dos mapas e seus modos de significar lugares e as suas relações, a perspectiva da semiótica peirciana traz novos e pertinentes insights (NöTH, I998, p. I23).

\section{Peirce e os signos cartográficos}

Charles Sanders Peirce (I839-I9I4) já havia chamado a atenção para a natureza semiótica dos mapas. Trabalhando para a U.S. National Geodetic Survey (NGS), Peirce dedicou longos anos de sua vida ao estudo da geodesia, o ramo da geofísica que se ocupa da determinação das dimensões e forma da Terra e de seu campo gravitacional. Nesta função, Peirce valeu-se amplamente de recursos cartográficos, pois a geodesia igualmente concerne à locação de pontos fixos e sistemas de coordenadas no território. Peirce também é o autor de um método cartográfico que é ainda hoje conhecido sob o nome de projeção quincuncial e cuja finalidade é a redução das distorções da representação das regiões do extremo norte (por ex., Groenlândia) e sul (por ex., Antártica) do globo, caraterísticas das tradicionais projeções cartográficas de Mercador (ver, por ex., Biodiversus, 2019).

No quadro da semiótica de Peirce, os elementos semióticos de qualquer mapa são signos. Um signo cartográfico representa um objeto. O objeto de uma representação cartográfica, isto é, o que o signo representa, é o segundo correlato da relação sígnica, e o terceiro correlato é o interpretante, que é o efeito provocado pelo signo. Para Peirce, signo e representação são essencialmente sinônimos: "De fato, a representação necessariamente envolve uma tríade genuína. Pois ela envolve um signo ou representamen de algum tipo, externo ou interno, mediando entre um objeto e um pensamento interpretador", o que pode se dar em uma mente humana ou não humana, até num dispositivo tecnológico (CP I.480, I896). Portanto, os mapas são signos complexos cujos elementos são signos cartográficos de natureza triádica:

Com Peirce, a natureza do signo cartográfico tem de ser entendida como triádica. O signo do mapa consiste primeiramente de um representamen, o mapa como ele está presente aos nossos olhos. Em segundo lugar, de um objeto ao qual ele se refere e que é grosseiramente o mundo geográfico, e, em terceiro lugar, o interpretante, quer dizer, a interpretação à qual ele dá origem. Cada um dos três correlatos pode ser de interesse distinto nos vários contextos dos estudos dos mapas. (NöTH, I998, p. I23-I24) 
Todo signo capta somente alguns aspectos de seu objeto. O signo nunca é capaz de representar seu objeto de maneira completa, pois há sempre uma sobra do objeto que o signo não pode capturar, como explica Santaella (2000, p. 23). Peirce distingue entre o objeto dinâmico e o objeto imediato do signo (CP 4.536, I905). O objeto imediato do signo cartográfico é o objeto como o mapa o representa, incompleto e sem todos os seus detalhes, enquanto o objeto dinâmico diz respeito ao território real, que o mapa quer representar.

Conforme o tipo de relação entre o signo e o objeto que ele representa, o signo cartográfico pode ser classificado como um ícone, um índice ou um símbolo. O signo cartográfico é um ícone, de maneira em que ele representa o seu objeto dinâmico por similaridade. Qualquer mapa do Brasil é similar ao território do país que ele representa, como mostram as fotografias aéreas do território.

O signo cartográfico é um índice quando possui uma conexão direta (causal, temporal ou espacial) com o seu território. A orientação do motorista, que usa um GPS no seu carro inclui um fundamento icônico na medida em que as imagens na tela mostram configurações que são semelhantes ao território que eles representam, mas a orientação do motorista é essencialmente indexical, quando ela orienta o usuário a virar ou não para a direita ou esquerda. Todo mapa do território do seu usuário indica um ponto que representa o ponto no qual se encontra o usuário. Peirce (CP 2.230, I9I0) exemplifica: "Em um mapa de uma ilha colocado sobre o chão daquela ilha deve haver, sob todas as circunstâncias ordinárias, alguma posição, algum ponto, marcado ou não, que representa qua lugar no mapa, o mesmo ponto qua lugar na ilha". Isso ocorre porque todo mapa se vale de um determinado tipo de projeção que é, em si mesma, "um feixe de linhas que divergem a partir de um ponto" (CP 8.I25, I902).

O símbolo, na definição de Peirce, é um signo que se baseia em convenções que precisam ser apreendidas. As palavras em língua portuguesa no mapa do motorista são símbolos. Praticamente nenhum mapa pode dispensar símbolos. Além de usar palavras como símbolos, a tradição cartográfica desenvolveu um código específico de símbolos cartográficos para representar cidades de vários tamanhos, rios, montanhas etc.

Peirce distingue entre ícones genuínos e ícones híbridos ou hipoícones, que compreendem as imagens. Um ícone genuíno tem "qualidades simples" em comum com o seu objeto, por ex., formas ou cores. Os ícones deste tipo "são tão completamente substituíveis pelos seus objetos que dificilmente são distinguidos deles" (CP 3.362, I885). Este tipo de 
ícone é pouco típico dos mapas. As suas cores, por exemplo, raramente representam o seu território por suas qualidades simples. As águas dos mares são mesmo azuis e as montanhas marrons, como o mapa os representa? A capital, que um mapa destaca em vermelho certamente não tem quase nada de vermelho no seu território. Portanto, os mapas são hipoícones, que misturam o iconicidade pura com outros tipos de iconicidade e até com índices e símbolos. Peirce distingue dois outros tipos de ícones, os diagramas e as metáforas (CP 2.276-278, 1902).

Dessa tipologia, os diagramas são os signos mais característicos dos mapas. Um diagrama representa por similaridade abstrata o seu objeto, focalizando as relações internas entre os objetos, que ele representa. O mapa diagramático se assemelha a seus territórios em função de relações análogas entre suas partes (CP 2.282, I893). Nos mapas do metrô de São Paulo predominam os signos diagramáticos. O que importa é que eles representam as relações entre as estações, não a topografia exata das trajetórias muitas vezes curvas do metrô entre eles (STJERNFELT, 2007, p. III).

A forte diagramaticidade dos mapas permite que um dos maiores atributos icônicos venha à tona. Segundo Peirce (CP 2.279, I895), a principal característica distintiva dos ícones manifesta-se em que, "pela sua observação direta, outras verdades concernentes a seu objeto podem ser descobertas, além daquelas que foram suficientes para determinar sua construção". Assim a representação diagramática de um território resulta não só em perda de informação (devido à estratégia representacional de abstração), mas também em ganhos. No mapa de um metrô, por exemplo, podemos ler qual é a conexão entre duas estações que menos nos obriga de trocar de trem.

Em resumo, um mapa diagramático "representa todos os pontos de uma superfície por meio de pontos correspondentes de uma outra superfície de tal maneira a preservar a continuidade intacta, não importa quão grande seja a distorção" (CP 4.513, I903). Os recursos gráficos do mapa são marcações gráficas pontuais, lineares e de área dispostas sobre um campo subdividido convencionalmente que representam um território geográfico (cf. Krampen, I994, p. 98). Portanto, um mapa é um signo gráfico híbrido e complexo. Peirce sintetiza os atributos e capacidades dos diagramas, que se destinam sempre a melhorar a compreensão acerca de um determinado fenômeno, bem como suas limitações:

Diagramas e figuras diagramatóidas têm como objetivo serem aplicadas à melhor compreensão de estados de coisas, sejam eles experienciados, lidos ou imaginados. Tal figura não pode, contudo, mostrar ao que ela objetiva ser aplicada; 
nem o pode qualquer outro diagrama disponível para tal propósito. O onde e quando da experiência particular, ou a ocasião ou outra circunstância identificadora da ficção particular à qual o diagrama deve ser aplicado, são coisas não passíveis de serem exibidas diagramaticamente. Descreva e descreva e descreva, e você nunca poderá descrever uma data, uma posição, ou qualquer quantidade [...]. Você pode argumentar que um mapa é um diagrama que mostra localidades; sem dúvida, mas não antes que a lei de projeção seja compreendida, nem mesmo sem que ao menos dois pontos no mapa sejam de alguma forma previamente identificados com pontos na natureza. Ora, como qualquer diagrama poderá realizar tal identificação? (CP 3.4I9, I892)

São essas limitações dos diagramas que evidenciam por que os mapas necessitam igualmente se valer de signos indexicais e simbólicos. Além de datas, posições e quantidades, nomes de localidades e outras convenções culturais, a própria forma de projeção escolhida, em que pese sua conexão causal com o objeto, possui uma natureza altamente convencional e até mesmo controvertida, sendo digna de ser problematizada, como será mostrado adiante.

\section{Mapas como dispositivos cognitivos}

Os mapas com os seus eixos horizontais e a verticais planificam o seu território, que é tridimensional. O mapa informa sobre a dimensão da profundidade do território por meios convencionais. $\mathrm{O}$ território alto é representado em marrom, o território baixo em verde e as profundidades dos mares por vários tons de azul. O código desta regra é traduzido pela legenda do mapa (cf. Martinelli, I99I, p. 9). Dessa forma, pode-se observar que é nos eixos horizontais e verticais que reside a maior carga da iconicidade diagramática dos mapas, enquanto a representação da profundidade do território exige um código de signos simbólicos baseados em convenções da cartografia: linhas de paralelos e meridianos, entre outros), inclusive permitindo a superposição de informação não geográfica sobre a geográfica.

A terceira dimensão visual, superposta ao plano bidimensional, não exclui a possibilidade de que ela também exista nas representações e visualizações cartográficas em 3D, que simulam as três dimensões do espaço e vão se tornando a cada dia mais sofisticadas em função dos avanços computacionais, a exemplo do Google Earth, que simula a dimensão da profundidade com técnicas avançadas, sem ser tridimensional na sua superfície. Assim, sempre existirão misturas e amálgamas entre essas três funções semióticas; como observado por Krampen (I994, p. 99), o con- 
junto de signos cartográficos que constituem um mapa é sempre definido formalmente e organizado em uma rede de inter-relações, compondo o que pode ser chamado de uma textura sígnica cartográfica.

De acordo com as colocações de Martinelli (I99I, p. 35) e para os propósitos deste estudo, pode-se conceituar a cartografia como a ciência da representação e do estudo da distribuição espacial dos fenômenos naturais e sociais, suas relações e suas transformações ao longo do tempo, por meio de signos cartográficos que reproduzem este ou aquele aspecto da realidade. Para o autor (ibid., p. 38), a cartografia possui uma função tríplice: registrar, tratar e comunicar informações, fazendo-se necessário considerar o valor cognitivo dos mapas, mobilizando-se, para tanto, a metodologia da representação cartográfica e sua respectiva linguagem.

$\mathrm{Na}$ literatura cartográfica é comum encontrar distinções tal como as que diferenciam entre a execução e o uso de um mapa, entre o emissor e o receptor da mensagem cartográfica ou também entre os dados e os mapas. Com base em termos semióticos aplicados, é possível desenvolver uma análise triádica dessas dicotomias, pois a semiótica fornece "definições e classificações gerais de todos os tipos de códigos, linguagens, signos, sinais etc. de qualquer espécie e dos principais aspectos que os envolvem, como explica Santaella (2002, p. 47).

A natureza triádica do signo permite analisá-lo, primeiramente, com base em seu potencial para significar advindo de suas propriedades internas de representação; em segundo lugar, em referência àquilo que ele indica ou representa e, em terceiro, nos tipos de interpretação que ele tem o potencial de gerar em seus usuários. Em função do caráter irredutivelmente triádico dos signos, pode-se observar que todo processo de representação está constituído desses três núcleos inter-relacionados: o signo cartográfico (Peirce o chama de representamen), o território, que é o seu objeto, e o interpretante. Todos eles podem ser respectivamente associados aos estratos de produção ou confecção de um mapa, referenciação dos dados mapeados e utilização do mapa. A Figura I representa o processo cartográfico e a suas três dimensões. 


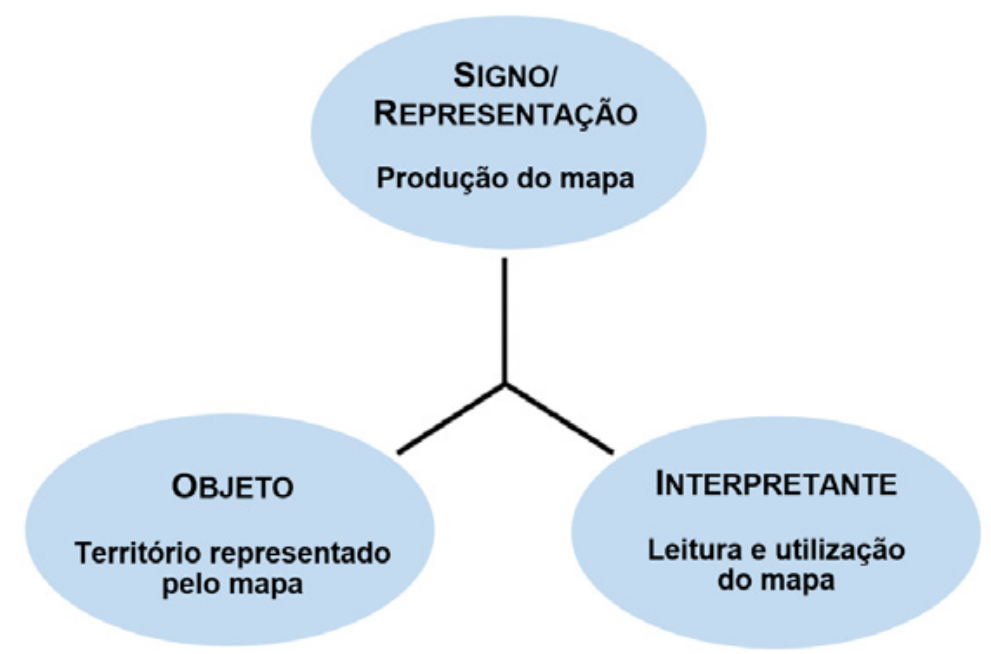

Figura I: Tríade signo-objeto-interpretante nos signos cartográficos.

Esses três núcleos cartográficos estão fortemente imbricados, não sendo possível traçar separações estanques entre eles, uma vez que toda representação cartográfica também pressupõe um território e uma interpretação. Contudo, é possível fazer distinções para fins de análise, combinando-as com as particularidades do fazer cartográfico, como indicado por Nöth:

O estudo dos meios visuais, das técnicas gráficas do design de mapas e dos determinantes perceptivos das cores, contrastes e padrões gráficos nos mapas focalizam o representamen cartográfico. A dimensão do objeto do mapa é posta em relevo nos estudos dos dados geodésicos, na geodesia dos satélites ou nas medidas topográficas. O correlato do interpretante é posto em relevo quando a interpretação dos mapas e as imagens mentais resultantes são focalizadas. (NöTH, I998, p. I24)

Inicialmente, a produção de um mapa envolve a criação de representações em função das possibilidades cartográficas disponíveis. Tais representações poderão ser qualitativas, quantitativas e dinâmicas, estas últimas destinadas a ir além de informações estáticas de um determinado estado de coisas, fornecendo informações de variações desses estados no tempo e no espaço, conforme Martinelli (I99I, p. I44). Esses tipos de representação podem ainda dispor a informação em diferentes níveis, seja de modo ordenado, ao expressar uma determinada hierarquia ou ordem em seus elementos, seletivo, mostrando distinções entre elementos, ou mesmo associativo, agrupando elementos de acordo com características comuns, como explica Duarte (2006, p. I89-I90). Nesse sentido, a produção de um mapa está baseada nos suportes, técnicas e conhecimentos cartográficos disponíveis em cada época. 
Os mapas combinam diversos tipos de informação e, de maneira geral, podem ser classificados de acordo com sua escala (grande ou pequena), função (referência geral, temáticos e cartas de navegação) e até mesmo por assunto, caso dos mapas temáticos, conforme Robinson et al. (I995, p. II-I7). Esta etapa não pode ser dissociada da anterior, pois caberá ao cartógrafo decidir a maneira pela qual representar o conteúdo de um mapa, e escolher o melhor tipo de recurso disponível para veicular cada tipo de informação com base em seus objetivos.

O usuário de um mapa se vê confrontado com um signo cartográfico, visto que utilizar um mapa é ler signos cartográficos. Na utilização do mapa se revela a sua eficácia cognitiva e comunicacional. O propósito de um mapa está em melhorar a visualização da informação, aumentar a sua retenção e facilitar a sua compreensão. Fica evidente, portanto, o quanto os três núcleos cartossemióticos (Figura I) se entrelaçam na prática cartográfica e como demandam o contínuo processamento cognitivo da informação. A leitura de um mapa demanda operações e esquematizações mentais que permitam que as três dimensões cartossemióticas sejam realizadas de modo eficiente, a fim de converter um mapa em um dispositivo cognitivo eficaz. A esse respeito, a própria cartografia se aproxima de uma ciência cognitiva:

Na utilização dos mapas estimula-se uma operação mental; há uma interação entre o mapa, como mero produto concreto e os processos mentais do usuário. Esse processo não se limita somente à percepção imediata dos estímulos, envolve também a memória, a reflexão, a motivação e atenção. Isto leva-nos a reconhecer que a cartografia tenderia para uma concepção muito próxima da de uma ciência cognitiva.

Mesmo nas outras etapas desencadeiam-se processos cognitivos entre as partes. A tomada de contato de quem faz o mapa com a realidade, problematizada para uma representação cartográfica, dinamiza a elaboração de um mapa mental. Há relações de ordem cognitiva também na etapa de confecção do mapa. Estas relações se dão entre o mapa mental do cartógrafo e o mapa cartográfico por ele construído, as quais envolvem operações de filtragem, seleção, classificação, simplificação e simbolização. (MARTINELLI, I99I, p. 38)

\section{Representações geográficas por imagens técnicas e tecnológicas desde a antiguidade}

Ao transpor para o plano bidimensional os seus objetos geográficos tridimensionais, os mapas criam formas referenciais nas quais é possível reconhecer e identificar os espaços representados. No contexto contempo- 
râneo é necessário atentar para a distinção entre técnica e tecnologia, sua relação com os seres humanos e como se diferenciam os mapas resultantes de ambas. A primeira, incorporada no rol das habilidades individuais, depende do fazer humano e de suas capacidades e instrumentos, e a segunda, introjetada na forma de tecnicidade em múltiplos dispositivos, expande essas capacidades, sofisticando-as:

No que diz respeito à distinção entre técnica e tecnologia, enquanto a primeira se caracteriza por habilidades que são introjetadas pelo indivíduo, a tecnologia envolve um dispositivo, aparelho ou máquina que é capaz de encarnar, fora do corpo humano, um saber técnico, um conhecimento científico acerca de habilidades técnicas específicas. Por isso, pode-se afirmar que a tecnologia é filha da revolução industrial. No que diz respeito à imagem, antes da industrialização, os instrumentos técnicos para sua produção eram prolongamentos do gesto hábil, concentrado nas extremidades das mãos, como é o caso do lápis, do pincel ou do cinzel. Já a tecnologia dá corpo a um saber técnico introjetado nos seus próprios dispositivos materiais. No campo da imagem, isso começou com a fotografia e foi se sofisticando cada vez mais no decorrer do século XX. (SANTAELla, 2OI2, p. 7I)

Assim, já os primeiros signos cartográficos conhecidos da história da humanidade foram imagens técnicas, fruto da habilidade de desenho e da capacidade de abstração. Mapas da Antiguidade e da Idade Média mostram como as representações têm auxiliado o ser humano a se orientar no espaço terrestre.
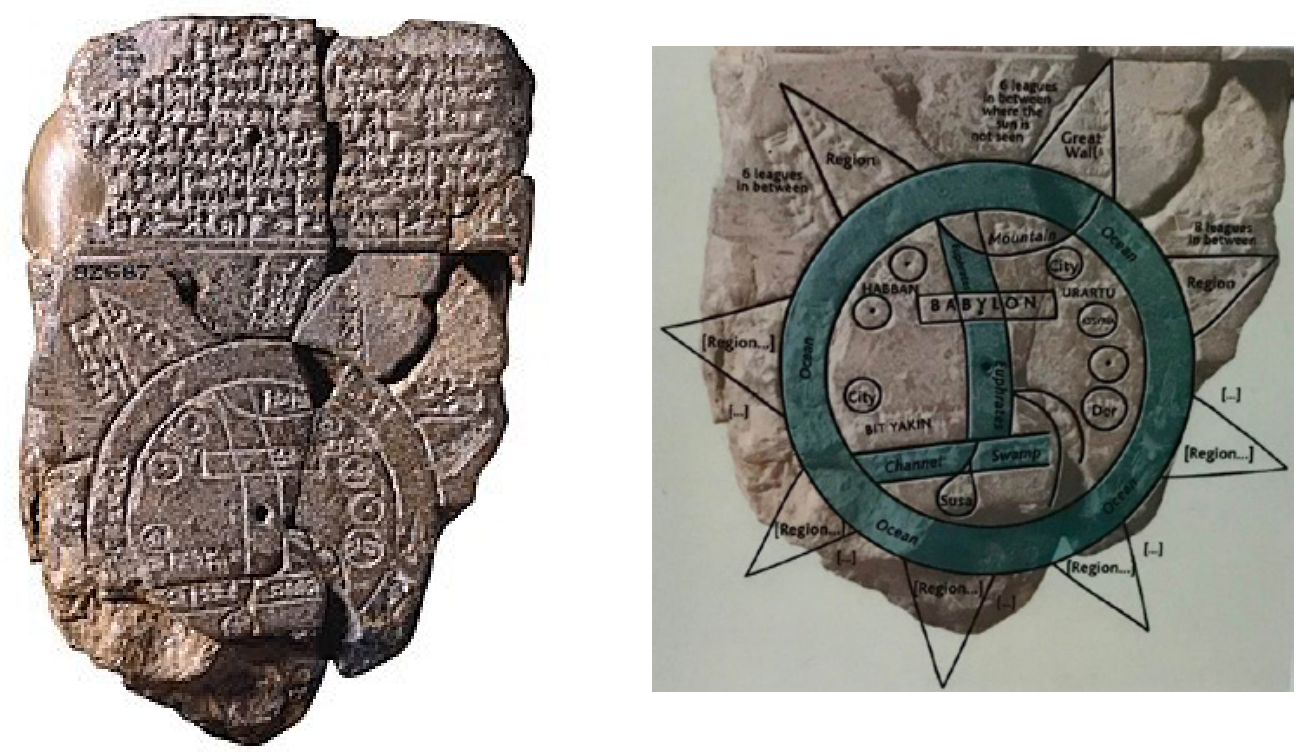

Figuras 2 e 3. Mapa-múndi Babilônio em escrita cuneiforme, século VI a.C, British Museum, e a transcrição de suas principais indicações. Disponível em: britishmuseum.org/research/collection_online/collection_object_details/collection_image_gallery. aspx? partid=I\&assetid $=3243600$ I\&objectid $=362000$ e londonist.com/london/museums-and-galleries/the-oldest-map-of-the-world-is-right-here-in-london.

Acessos em: or jun. 2019. 
As Figuras 2 e 3 mostram o mais antigo mapa-múndi conhecido da história humana, que data do século 6 a. C., e do qual Andrews dá a seguinte descrição:

O primeiro mapa-múndi conhecido da história foi desenhado em uma tabuleta de argila na antiga cidade da Babilônia, por volta de 600 a.C. O mapa em forma de estrela mede apenas cinco por três polegadas e mostra o mundo como um disco plano cercado por um oceano, ou "rio amargo". A Babilônia e o rio Eufrates são representados no centro como um par de retângulos, enquanto as cidades vizinhas da Assíria e Susa são mostradas como pequenas bolhas circulares. Fora do disco, há uma coleção de cunhas triangulares, que retratam ilhas distantes com nomes misteriosos como "além do voo dos pássaros" e "um lugar onde o sol não pode ser visto". O texto cuneiforme que o acompanha descreve essas terras desconhecidas como sendo povoadas por bestas mitológicas, o que sugere que o mapa mostra tanto características geográficas reais como elementos da cosmologia babilônica. (ANDREws, 20I8)

Essa primeira imago mundi, mistura de conhecimentos empíricos e crenças místicas sobre o céu e a terra (ver também British Museum, 20I9), faz parte de uma épica jornada para compreender a extensão do planeta e a disposição de suas massas de terra e água. Trata-se de um signo geográfico altamente diagramático, que representa o seu território, isto é, o seu objeto dinâmico, numa forma muito primitiva. Apesar da rudimentar semelhança com o território mapeado, tal como o conhecemos hoje como uma realidade geográfica, e sem corresponder a uma escala matemática, trata-se, ainda assim, de um diagrama do seu território. Por meio da sua abstração, o mapa dá valiosas informações que permitiram aos seus usuários, já naquela época, ter uma visão inicial do seu entorno geográfico.

Para Joly (2013, p. 26), a diferença entre simples esboços tal como o mapa babilônico e mapas propriamente ditos reside em que os mapas se baseiam em uma rede geometricamente construída. Como observa Duarte (2006, p. 30), foram os gregos, que estabeleceram as "bases científicas da moderna Cartografia" ao fornecer seus primeiros elementos, compilando os dados disponíveis e criando técnicas projetivas, lançando as bases de uma cartografia racional matematicamente fundamentada, livre de crenças religiosas e mistificações.

Com o Renascimento e as viagens de exploração de novos continentes, a cartografia europeia ganhou novos impulsos pela necessidade de contar com mapas mais precisos e atuais. Dando prosseguimento a trabalhos de antecessores como Martin Waldseemüller (cf. I475-I522) que, em seu planisfério, figurou e nomeou a América pela primeira vez em I507, 
o cartógrafo mais inovador desta época foi Gerardus Mercator (I5I2-I594). Mercator criou o sistema de projeção cilíndrica, utilizado com modificações até hoje, com os seus meridianos retilíneos equidistantes e paralelos retilíneos progressivamente espaçados entre si em direção aos polos. Essa técnica foi idealizada para o famoso mapa-múndi em i 8 folhas de 1569 de Mercator. O avanço do conhecimento cartográfico entre os séculos XXVI e XVIII resultou em representações cartográficas cada vez mais exatas dos seus territórios. O progresso da cartografia neste período reflete não só o avanço do conhecimento cartográfico nestes séculos. Ele também exemplifica a influência crescente da realidade geográfica sobre as suas representações cartográficas, e nisso a influência que o objeto dinâmico exerce sobre o signo que o representa, conforme a semiótica dinâmica de Charles S. Peirce (NöTH, 20I2, p. 343).

Do século XVII em diante, a cartografia expandiu-se progressivamente até chegar a seus desenvolvimentos topográficos em grande escala. A contribuição de Mercator permeou todos esses desenvolvimentos. Porém, seu sistema de projeção tinha a bem-conhecida desvantagem de representar os territórios do Sul e do Norte do globo de forma ampliada em relação aos territórios equatoriais e centrais, como ilustrado nas Figu$\operatorname{ras} 4,5$ e 6 .
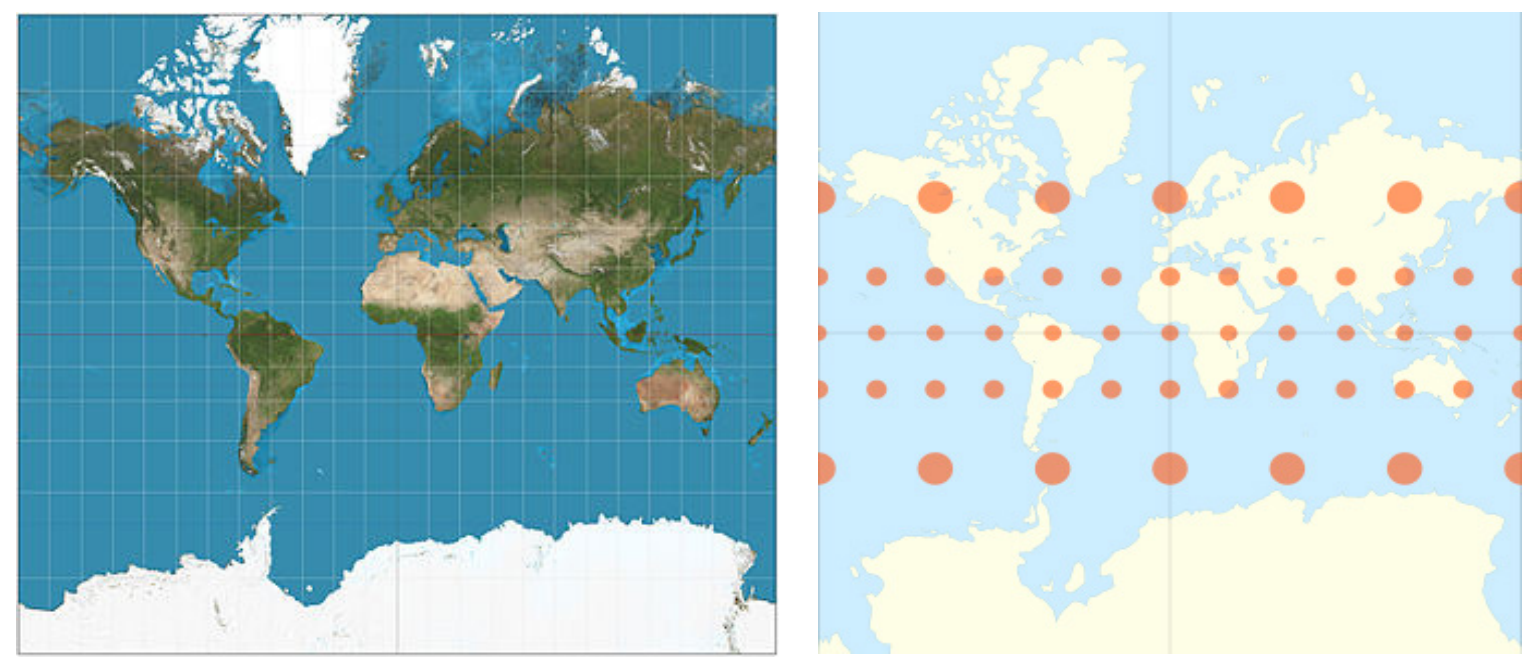

Figuras 4 e 5. Projeção de Mercator do mundo entre 82fflS 82fflN, acompanhada do marcador de deformação de Tissot sobre a projeção de Mercator. Disponivel em: en.wikipedia.org/wiki/Mercator_projection. Acesso em: or abr. 20 I9. 


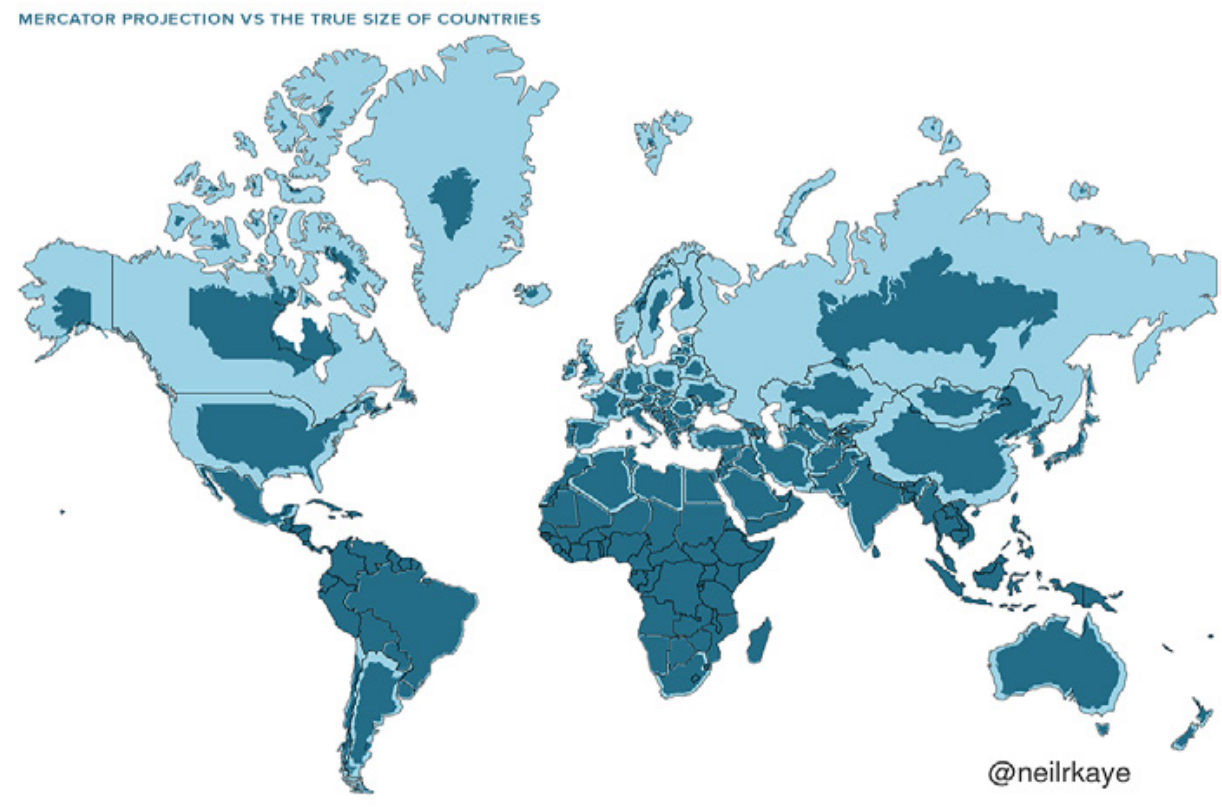

Figura 6. Projeção de Mercator acrescida do verdadeiro tamanho de cada país, cuja área se distorce e aumenta progressivamente à medida que se afasta do Equador. Imagem criada por neilrkaye, usuário de Reddit (cf. RouTLEY, 20I8). Disponível em: visualcapitalist.com/mercator-map-true-size-of-countries. Acesso em: o7 jul. 2019.

Ao comentar o criativo mapa (Figura 6) que sobrepõe o real tamanho dos países à projeção de Mercator, Routley (20I8) observa o quanto os mapas são importantes para formar nossas macropercepções geopolíticas e ambientais. Embora essa projeção ainda seja útil para fins de navegação, ela se mostra insuficiente para propósitos educativos, por aumentar artificialmente o tamanho de países na mente daqueles cujo conhecimento ainda se baseia nesse que se tornou o mapa-múndi mais conhecido. Por isso,

os críticos da projeção de Mercator argumentam que o uso continuado desse estilo de mapa dá aos usuários um senso distorcido do tamanho real dos países, especialmente no caso do continente africano. O mapa de Mercator também aumenta inadvertidamente os tamanhos da Europa e América do Norte. Em termos visuais, o Canadá e a Rússia parecem ocupar aproximadamente $25 \%$ da superfície da Terra, quando na realidade ocupam apenas $5 \%$. (Routley, 20I8)

Fazendo frente ao desafio cartográfico de encontrar meios de corrigir as distorções que caracterizam os mapas do tipo Mercator, Charles S. Peirce, em I879, propôs um novo sistema de projeção, que ele denominou de quincuncial. Este sistema representa e organiza a representação gráfica do nosso globo a partir de cinco centros no mapa, por isso chamado "quincuncial". Como mostrado na Figura 7, dos cinco centros, um se localiza no centro do mapa, mais especificamente no polo Norte, e os 
outros quatro estão situados nos quatro cantos do mapa, e fazem referência ao polo Sul. Essa técnica reduz a deformação das representações para $20 \%$, concentrando o maior grau de deformação remanescente nos oceanos, como mostrado na Figura 8 pelos quatro círculos grandes, e na qual os demais marcadores mostram também a inexistência de deformação ao centro (círculo pequeno ao centro) e a pouca deformação nas áreas territoriais (demais círculos médios ao redor). Não sem um certo orgulho, Peirce (CP 4.5I3, I903) fala do seu novo sistema de projeção cartográfica como resultando em "um mapa perfeitamente correto".
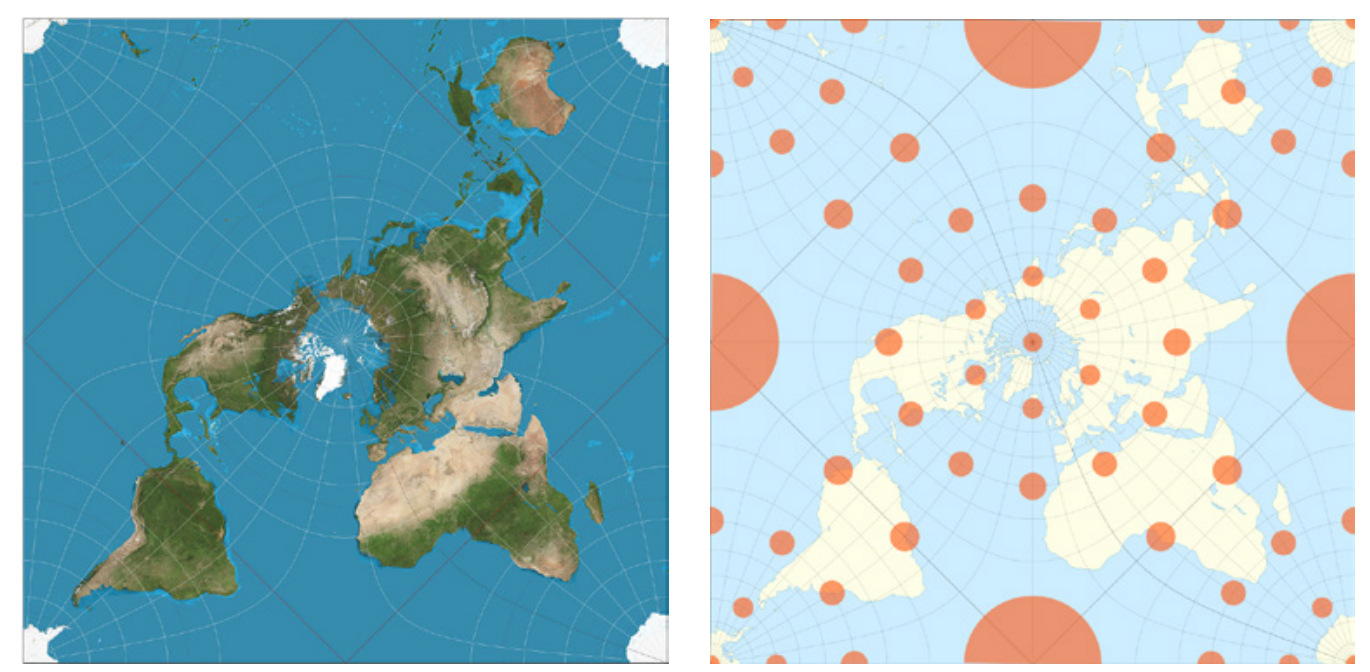

Figuras 7 e 8. Projeção quincuncial de Peirce, acompanhada do marcador de deformação de Tissot sobre a projeção de Peirce. Disponível em: en.wikipedia.org/ wiki/Peirce_quincuncial_projection. Acesso em: or abr. 20 I9.

Além das projeções cilíndricas de Mercator e quincunces de Peirce, existem vários outros sistemas de projeção cartográfica. A partir da década de I960, as operações geodésicas, topográficas e cartográficas aperfeiçoaram-se e aceleraram-se de maneiras nunca antes imaginadas. A possibilidade de fotografar a Terra expandiu sobremaneira nossa percepção do planeta e, às técnicas geométricas e analíticas de projeção, vieram somar-se a captação e transmissão de dados via satélite, bem como os sistemas de posicionamento global para navegação, transformando mapas em imagens tecnológicas (cf. JungK, 20I6). Atualmente, para além do conhecido mapa-múndi de proporções pouco adequadas e criticado como eurocêntrico, comum em livros didáticos, recursos computacionais permitiram a criação de um mapa fiel para representar a área dos continentes.

Conforme o site do Narukawa Lab (Authagraph, 2015), em I999, o artista e arquiteto japonês Hajime Narukawa criou o Authagraph, mapa que reflete com precisão as proporções das áreas de países e continentes, 
embora ligeiramente deformados. Narukawa se inspirou na tradicional arte japonesa de dobraduras em papel, o Origami. De acordo com MacDonald (20I8), o globo terrestre foi dividido em 96 triângulos e transformados em tetraedros (poliedros de quatro faces), como mostra a Figura 9. Como poliedros são formas geométricas de faces planas e volumes definidos, isso possibilitou exibir as informações esféricas da Terra em um retângulo, mantendo a proporção de suas áreas.

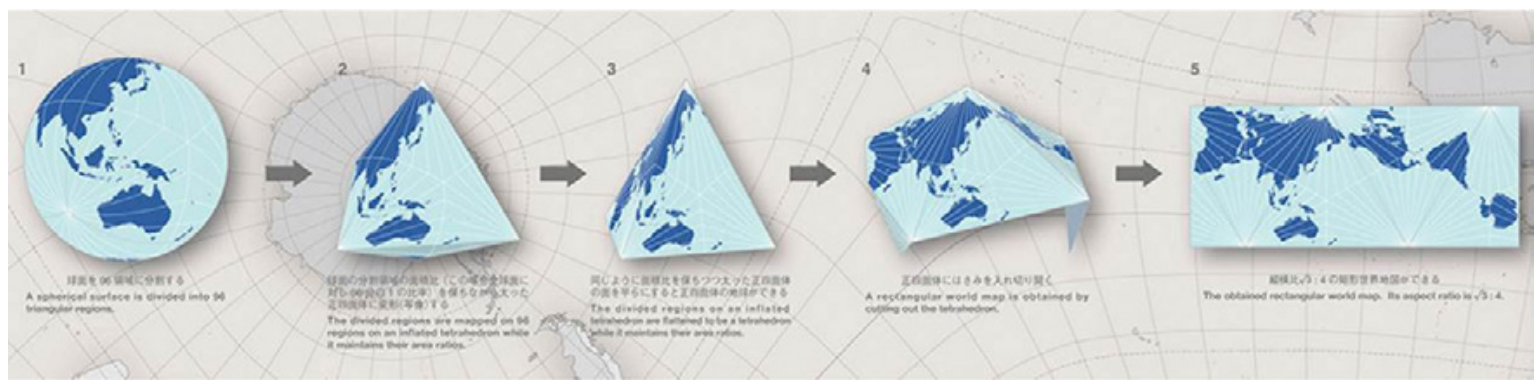

Figura 9. Passos na confecção do mapa: (I) Uma superfície esférica é dividida em 96 regiões triangulares. (2) As regiões divididas são mapeadas em 96 regiões em um tetraedro inflado ao mesmo tempo que ele mantém as proporçôes das áreas. (3) As regiões divididas em um tetraedro inflado são planificadas em um tetraedro, ao mesmo tempo em que mantém as proporções das áreas. (4) Um mapa retangular do mundo é obtido a partir do tetraedro. (5) O mapa-múndi obtido, apresentado na proporção de raiz quadrada de 3 para 4 . Disponível em: demilked.com/accurate-world-map-scale-design-japan-hajime-narukawa. Acesso em: or abr. 20I9.

O mapa, que não visa à navegação, mostra o Oceano Pacífico ao centro, com a Ásia à esquerda e a América à direita, o que parece pouco habitual à primeira vista (Figura Io). O Authagraph foi adotado como a ferramenta cartográfica oficial da Japanese National Museum of Emerging Science and Innovation (Miraikan) e vem sendo utilizado em livros didáticos oficiais para o segundo grau no Japão há alguns anos, como informa o Narukawa Lab (Authagraph, 20I5). Em 20I6, o Authagraph recebeu um dos mais importantes prêmios de design do Japão, o Good Design Grand Award (GDA, 20I6), concedido pelo Instituto de Promoção de Design Japonês. "Authagraph representa fielmente os oceanos e os continentes, incluindo a Antártida, e fornece uma perspectiva precisa e moderna do nosso planeta", disse a organização que concedeu o prêmio a Narukawa, que também observou que o mapa ainda poderá ser mais elaborado, aumentando o número de subdivisões e melhorando a precisão, conforme a redação do noticiário (BВC MuNDO, 20I6). 


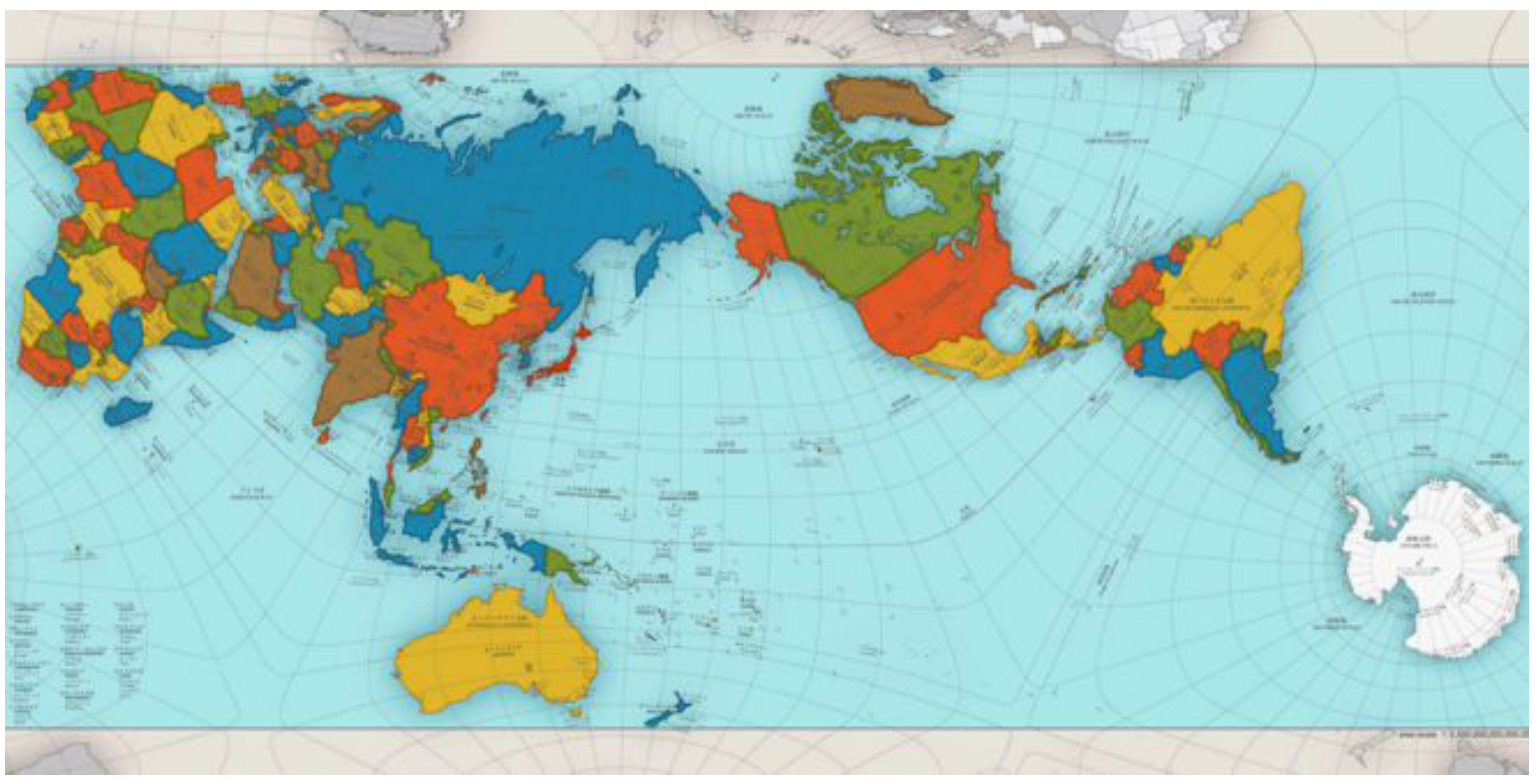

Figura ro. Mapa-múndi Autagraph, criado pelo arquiteto japonês Hajime Narukawa.

Disponível em: bbc.com/portuguese/curiosidades-37864328. Acesso em: or abr. 2019.

\section{Intepretação dos signos cartográficos}

Conhecer e representar a Terra é o objetivo da cartografia. Porém, nenhum mapa é e nem pode ser o seu território. Como alerta Franco (20I4, p. I87), mapas devem ser investigados como tecnologias cognitivas, pois "o simples acúmulo de dados (índices) não garante que conseguiremos elaborar generalizações e produzir pensamento", o que mostra a relevância dos mapas como possibilidade de design e para a visualização da informação capaz de permitir esse salto semiótico (ibid.). Para Ribeiro (20I8, p. 4I), torna-se evidente "como a cartografia crítica pode ajudar a repensar a natureza dos mapas. Para isso, é fundamental desvendar não somente que tipo de conhecimento os mapas produzem, mas também, como eles seriam capazes de produzir outros conhecimentos" (ibid.). O autor frisa a importância de valorizar iniciativas de refletir sobre as representações do espaço, problematizando o real a fim de produzir conhecimento crítico:

O pensamento crítico sobre a cartografia permite que alternativas de se pensar o espaço sejam valorizadas. O mapeamento não é, portanto, um mero reflexo da realidade, mas sim, uma forma de produzir conhecimento. Esse conhecimento pode emergir a partir de um olhar crítico sobre as relações de poder contidas nas representações cartográficas do espaço. Nesse sentido, a cartografia crítica procura ver o mapa não como representação do real, mas sim como um signo de problematização do real, justamente expondo suas falhas, contradições e desordens. (RIBEIRo, ibid.) 
Com o advento das tecnologias digitais de navegação nas telas dos nossos computadores e celulares, os mapas impressos em papel começam a se tornar obsoletos. Contudo, imagens com base em projeções cartográficas tradicionais continuam a ser utilizadas, reforçando representações distorcidas de países e continentes de maneira que a sua relevância no concerto das nações não corresponde à realidade. Em uma época em que os recursos naturais e a questão da sustentabilidade ganham cada vez mais importância nos debates internacionais (econômicos, ecológicos, políticos, sociais etc.), a visão do nosso globo precisa ser repensada. O desafio cartográfico de projetar um planeta esférico em um mapa plano permanecerá, mas o rigor científico inerente aos sistemas de projeção da cartografia tradicional continua a afetar sua visualização. Ao não ser colocado sob análise, ele pode perpetuar distorções ideológicas.

A exemplo do inovador mapa japonês, outras explorações visuais inovadoras vêm sendo feitas, especialmente no âmbito das estéticas tecnológicas. A obra da artista, pesquisadora e professora brasileira radicada no País Basco Cristina Miranda, intitulada My Walled Google Earth (2019), o que pode ser traduzido como "meu Google Earth amuralhado", explora a questão das fronteiras conflituosas no planeta, transformando-as em bordas circulares, evidenciando a oposição exterior/interior e as consequentes separações e limitações que elas engendram (Figuras II e I2).
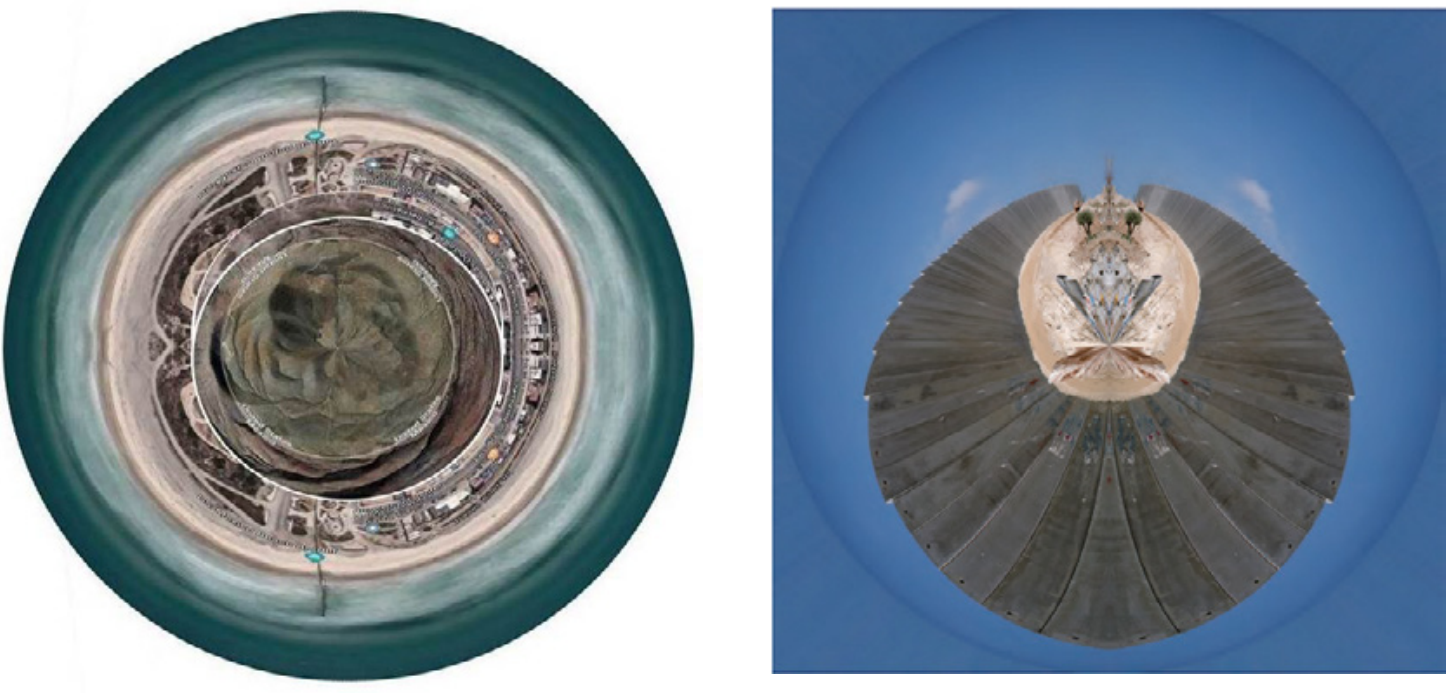

Figuras II e I2. My Walled Google Earth @Tijuana-San Diego Border - Coordenadas GPS 32.54238I, II7.029I79; e My Walled Google Earth@Israeli-Palestinian West Bank Barrier, I949 Armistice Line, Green Line - Coordenadas GPS 31.252633, 34.533329. Exposição My Walled Google Earth, Getxo Kultur Etxea, 5-28.04.20I9, País Basco. Disponível em: getxo.eus/es/servicios/detalle-evento/7II4 e getxo.eus/DocsPublic/cultura/20I9/my_wallet.pdf. Acessos em: io abr. 20I9. 
O trabalho mostra que é possível lançar um olhar crítico inclusive sobre as mais recentes tecnologias cartográficas, como Google Maps e Google Earth, nos quais esses limites parecem não existir em função da fluidez de navegação em um espaço digitalmente representado. As imagens tecnológicas de Miranda (Figuras II e I2) exibem uma estética ímpar, na qual muros, muralhas e fronteiras e suas geolocalizações ao redor do mundo são iconizados, apresentados sob uma perspectiva caleidoscópica, que transforma barreiras físicas em objetos moldáveis, originais mandalas imaginárias, que subvertem barreiras reais no âmbito do virtual, semeando, assim, o simbólico com novas formas de perceber e sentir:

Eu tento ir mais além da atitude de usuária dos aplicativos Google Maps e Google Earth para usá-los a partir de um enfoque poético. Utilizando ambos os aplicativos para viajar digitalmente através da representação do planeta, recolho imagens de muros encontrados, fragmentos digitais geolocalizados, que transporto para uma obra que procura revelar a contradição existente entre a concepção fluida de viagem através de um espaço tecnologicamente mediado, digitalmente explorado e representado, e as barreiras que nos dividem no mundo físico e nos espaços sócio-políticos que habitamos. (Miranda, 20I9, p. 4)

Se cada projeção cria uma imagem cartográfica diferente de nosso planeta e muitas formas novas de visualização podem ser produzidas, em termos educativos, cotejar diferentes representações da Terra pode contribuir para compreender a diferença entre o planeta em si mesmo e sua representação, desenvolvendo o senso crítico, levando a um ganho de consciência semiótica. Isso certamente contribuirá para a compreensão do mundo que habitamos e fomentará novas perspectivas. Os procedimentos de construção cartográfica, sua iconicidade, indexicalidade e simbolicidade, bem como os processos de interpretação dos mapas deverão ser sempre colocados sob escrutínio, pois sua leitura inevitavelmente acarreta juízos de valor. Ao pensar os mapas sob a perspectiva semiótica, pode-se explorar as fronteiras da cartografia, subvertendo antigos paradigmas, como tem sido feito ao longo da história.

\section{Referências}

ANDREWs, Evan. Remarkable early maps: explore eight of the most important maps from the early history of cartography. (Newsletter) History. Publicado em: 22 ago. 20I8. Disponível em: history.com/ news/8-remarkable-early-maps. Acesso em: I3 jun. 2019.

Authagraph, Map: theory of Earth system design. Narukawa Lab, 20I5. Disponível em: narukawa-lab.jp/archives/authagraph-map. Acesso em: I3 jun. 2019 . 
BbC Mundo, Redação. O criativo mapa que mostra o mundo como realmente é. BвC MUNDO. Publicado em: 04 nov. 20I6. Disponível em: bbc.com/portuguese/curiosidades-37864328. Acesso em: I3 jun. 2019. Bertin, Jacques. Sémiologie graphique: les diagrammes - les réseaux les cartes. Paris: Les ré-impressions des Editions de L'Ecole des Hautes Etudes en Sciences Sociales, I999.

Biodiversus. Projeção quincuncial de Peirce. Pulicado em: i6 abr. 2019. Disponível em: instagram.com/p/Bv662jQgvsS. Acesso em: I5 jun. 2019 .

British Museum. Collection online: the map of the world. British Museum, 20I9. Disponível em: britishmuseum. org/research/collection_online/collection_object_details. aspx? assetId=40448500I\&objectId=362000\&partId=I. Acesso em: I3 jun. 2019 .

BRown, Matt. The oldest map of the world is here in London. Londonist. Pulicado em i9/02/20I8. Disponível em: londonist.com/london/ museums-and-galleries/the-oldest-map-of-the-world-is-right-here-inlondon. Acesso em: I3 jun. 2019.

Duarte, Paulo Araújo. Fundamentos de cartografia. 3 ed. Florianópolis: Ed. da UFSC, 2006.

Franco, Juliana de Oliveira Rocha. Cartografias subversivas em mídias locativas. Tese (Doutorado em Comunicação e Semiótica) - Faculdade de Filosofia, Comunicação, Letras e Artes. Pontifícia Universidade Católica de São Paulo, 20I4.

Cartografias criativas: da razão cartográfica às mídias móveis.

Curitiba: Appris, 2019.

GDA, Good Design Award. Good Design Grand Award, 20I6. Disponível em: g-mark.org/award/describe/44527. Acesso em: 27 jul. 2019.

Joly, Fernand. A cartografia. I5 ed. Campinas: Papirus, 2013.

Jungk, Isabel. Expansão da percepção pela fotografia. Caderno 16ffi Jornada Peirciana do Centro Internacional de Estudos Peircianos. São Paulo: CIEP-TIDD, 2016, v. I6. p. 148-162.

Krampen, Martin. Cartography. In: Encyclopedic dictionary of semiotics. 2 ed., revised \& updated, v. I, Seвzor, Thomas A. (org.). Berlin: Mouton de Gruyter, I994, p. 98-99.

MaCdonALD, Fiona. This bizarre world map is so crazily accurate; it actually folds into a globe. Science Alert. Publicado em: 04 set. 2018. Disponível em: sciencealert.com/world-map-authagraph-origami-globehajime-narukawa. Acesso em: I3 jul. 20I9. 
Martinelit, Marcello. Curso de cartografia temática. São Paulo: Contexto, I99I.

Miranda, Cristina. My walled Google Earth: exhibition catalogue.

Getxoko Kultur Etxea, Sala Torrene (5-28 abr. 20I9), Getxo, País Basco, 20I9. 28 p. Disponível em: getxo.eus/es/servicios/detalle-evento/7II4. Acesso em: 13 jun. 2019 .

Nöтн, Winfried. Cartossemiótica. In: Visualidade, urbanidade, intertextualidade. Olviera, Ana Claudia Mei Alves de; Brito, Yvana Carla Fechine de (orgs.), São Paulo: Hacker, I998, p. II9-I33.

Medieval maps: hybrid ideographic and geographic sign systems. In: Herrschaft verorten: politische kartographie des mittelalters und der frühen neuzeit. BAUmGäRTnER, Ingrid; STERCKen, Martina (orgs.), p. 335-353. Zürich: Chronos, 2012.

Peirce, Charles S. Collected papers. v. i-6, C. Hartshorne, Charles; Weiss, Paul (orgs.); v. 7-8, I93I. Burks, Arthur W. (org.). Cambridge, MA: Harvard University Press, I958. (Citado como CP, seguido do número do volume, ponto e número do parágrafo, e seguido pelo ano do manuscrito ou da publicação do referido texto).

Ribeiro, Daniel Melo. Limiares da cartografia: deambulação, arqueologia e montagem no mapeamento de lugares. Tese (Doutorado em Comunicação e Semiótica) - Faculdade de Filosofia, Comunicação, Letras e Artes. Pontifícia Universidade Católica de São Paulo, 2oı8.

Robinson, Arthur H. et al. Elements of cartography. 6 ed. New York, NY: Wiley, I995.

RoutLey, Nick. Mercator misconceptions: clever map shows the true size of countries. Visual capitalist. Publicado em: o9 nov. 2018. Disponível em: visualcapitalist.com/mercator-map-true-size-ofcountries. Acesso em: I3 jun. 2019.

Santaella, Lucia. Leitura de imagens. São Paulo: Melhoramentos, 20 I2. Semiótica aplicada. São Paulo: Pioneira Thomson, 2002. Teoria geral dos signos: como as linguagens significam as coisas. São Paulo: Pioneira Thomson, 2000.

Stjernfelt, Frederik. Diagrammatology: an investigation on the borderlines of phenomenology, ontology and semiotics. Dordrecht: Springer, 2007. 